\title{
How informed is patients' consent to release of medical information to insurance companies?
}

\author{
Robert E Lorge
}

\begin{abstract}
A study was conducted to assess how informed the consent of patients is to the release of confidential information to insurance companies. Questionnaires were sent to 226 consecutive patients from four practices whose general practitioners had received requests to complete a personal medical attendant's report for an insurance company. In total 195 patients returned the questionnaire, whose six questions required only a yes or no answer. More than half of the patients $(102(52 \%))$ could not recall having given their consent and $79(40 \%)$ had one or more objections to the questions commonly asked by insurance companies. Questions about sexually transmitted diseases and AIDS led to the greatest proportion of objections $(85 \%(67 / 79)$ and $80 \%$ (63/79) respectively). Over half $(111(57 \%)$ of the 195 respondents expected their doctor to withhold sensitive information. Of the 93 patients who gave their informed consent, $63(68 \%)$ did not expect that their doctor would be asked to answer one or more of the common questions.
\end{abstract}

In most cases the consent of patients to the release of confidential information to insurance companies is neither knowingly given nor informed.

\section{Introduction}

Before the compulsory registration of births, deaths, and marriages in 1837 life insurance premiums were set arbitrarily. By 1854, with the accumulation of statistics, insurance companies were able to base premiums on an individual person's life expectancy, and life insurance became more universally available.'

Mills, an underwriter, states that the final decision "in spite of sophisticated rating systems and underwriting manuals relies heavily on judgement,"' hence the importance of the personal medical attendant's report. Interestingly, $90 \%$ of applications for life insurance are accepted at normal rates. ${ }^{2}$ Life insurance companies usually write to general practitioners for medical information stating that they have the patient's consent to do so. The completed form enables the companies to assess relative risk and set appropriate premiums. With the upsurge of AIDS questions about patients' risk of developing the syndrome and about the results of any tests for HIV have become universal and doctors' disquiet at releasing medical information to third parties has increased.

The Surgery, Overton, Near Basingstoke, Hampshire RG25 3JP Robert E Lorge, MRCGP, general practitioner

Br.Med F 1989;298:1495-6

\section{Methods}

Four practices participated in the study. A questionnaire was sent to 226 consecutive patients whose general practitioners had been asked to complete a personal medical attendant's report for an insurance company. Patients applying for more than one policy were sent only one questionnaire, which was on a single side of A4 paper and consisted of six questions that required only a yes or no answer.

(1) Do you recall signing a consent form for your doctor to release your medical details?

(2) Did you expect your doctor to be approached by your insurance company to release your medical details?

(3) Are you aware that companies may ask for details of blood pressure readings, treatment, urine tests, past illnesses, smoking habits, drinking habits, family history, sexually transmitted diseases, past operations, drug abuse, and whether your doctor knows of anything in your lifestyle that would put you at risk of developing AIDS?

(4) Do you have any objections to the above questions being asked?

(5) Would you expect your doctor to withhold sensitive information?

(6) Were you aware that having been given your consent your doctor would normally be obliged to answer any detailed questions?

\section{Results}

Of the 226 questionnaires sent 195 were completed. Of the 195 respondents, 102 (52\%) could not remember having given their consent, whereas 93 $(48 \%)$ could. By contrast $144(74 \%)$ respondents expected that their doctor would be approached to release their medical details.

Patients' understanding of the content of the personal medical attendant's report is shown in table I.

TABLE I-Responses of 195 patients to third question on questionnaire. V'alues are numbers (percentages) of respondents

\begin{tabular}{lrr}
\hline & Yes & No \\
\hline $\begin{array}{lr}\text { Are you aware that companies may ask for details of: } \\
\text { Blood pressure readings }\end{array}$ & $123(63)$ & $72(37)$ \\
Treatment & $138(71)$ & $57(28)$ \\
Urine tests & $105(54)$ & $90(46)$ \\
Past illnesses & $164(84)$ & $31(15)$ \\
Smoking habits & $141(72)$ & $54(27)$ \\
Drinking habits & $123(63)$ & $72(37)$ \\
Family history & $123(63)$ & $72(37)$ \\
Sexually transmitted diseases & $86(34)$ & $109(55)$ \\
Whether any doctor knows of anything in your lifestyle & \\
that would put you at risk of developing AIDS & $74(38)$ & $121(62)$ \\
Past operations & $158(81)$ & $37(19)$ \\
Drug abuse & $129(66)$ & $66(34)$
\end{tabular}

Most anticipated questions on past illnesses and operations. Over $70 \%$ expected details of both their treatment and smoking habits to be given. Nearly two thirds of them were aware that details of their blood pressure recordings, drinking habits, family history, and any history of any drug abuse would be asked for. A smaller proportion expected inquiries about urine tests, sexually transmitted diseases, and risk factors for AIDS.

Seventy nine patients ( $40 \%$ ) objected to one or more 
of the questions commonly asked by insurance companies, $112(58 \%)$ had no objection, and four $(2 \%)$ were undecided. Even among the 93 patients who recalled having given consent, $63(68 \%)$ did not expect that their doctor would be asked to answer one or more of the common questions and $34(37 \%)$ had at least one objection.

Table II shows the objections to the questions commonly asked by insurance companies. Most objections were to questions on sexually transmitted diseases and AIDS. The numbers of objections to inquiries into family history, alcohol consumption, and drug abuse were similar. A third of the objections were to inquiries about smoking and a quarter to details of past illnesses and results of urine tests. Comparatively few objections were about the insurance company asking for details of treatment and blood pressure readings.

Over half the patients $(111(57 \%))$ expected their general practitioner to withhold information on items of a sensitive nature; $70(36 \%)$ did not expect their general practitioner to do so and $14(7 \%)$ did not know.

In total $107(55 \%)$ patients were aware that their doctor would be obliged to answer any detailed questions after having been given their consent, 86 $(44 \%)$ were not aware, and two $(1 \%)$ were undecided.

TABLE II-Objections to questions shown in table I

\begin{tabular}{lccc} 
Subject of question & $\begin{array}{c}\text { No of } \\
\text { objections } \\
\text { objectors respondents } \\
(\mathbf{n}=79)\end{array}$ & $\begin{array}{c}\text { As } \% \text { of all } \\
(\mathrm{n}=195)\end{array}$ \\
\hline Blood pressure readings & 13 & 16 & 7 \\
Treatment & 15 & 19 & 8 \\
Urine tests & 21 & 27 & 11 \\
Past illnesses & 21 & 27 & 11 \\
Smoking habits & 27 & 34 & 14 \\
Drinking habits & 34 & 43 & 17 \\
Family history & 36 & 46 & 19 \\
Sexually transmitted diseases & 67 & 85 & 34 \\
Risk of developing AIDS & 63 & 80 & 32 \\
Past operations & 14 & 17 & 7 \\
Drug abuse & 34 & 43 & 17
\end{tabular}

\section{Discussion}

My results may have underestimated the number of patients who could not recall having given their consent to the release of confidential information to insurance companies because general practitioners from one of the participating practices routinely seek written consent from their patients. One patient claimed not to have applied for a life insurance policy. It transpired that her husband had taken out a policy on her life without her knowledge. This seems not to be an isolated case.

The relationship between general practitioners and insurance companies may be awkward. ${ }^{+}$General practitioners usually act in their patients' best interests, but when filling in a personal medical attendant's report their contract is with the insurance company. Sometimes disclosure of confidential information will be contrary to the patient's interests, so that paradoxically general practitioners with well organised, easily retrievable records that include information such as alcohol and tobacco consumption may do their patients a disservice, whereas those who keep poor records may benefit their patients.

AIDS is predicted to be among the main causes of death in the United States by 1991 and the commonest cause among those aged $25-44$ - the group of people most likely to take out life insurance. Not surprisingly therefore most companies in the United Kingdom wish to ascertain whether an applicant is in a category of high risk behaviour. This forces general practitioners to make social rather than medical judgments, which many find disquieting.
A recent study showed that half of the patients attending a clinic for AIDS did not wish their general practitioner to be informed because they feared disclosure to others, including insurance companies. If general practitioners are to continue completing reports for insurance companies that include such sensitive questions, the patient's consent must be informed and freely given. My results suggest that this is not the case.

I thank Drs J Eustace, Swati Patel, and David Wright and their partners for their participation. I thank Dr R Coppin, Dr P Burke, and Professor J Bain for their helpful comments and useful criticism, and also Dr E Louise Draper for helping to draft the questionnaire.

1 Mills $W_{A}$. Life insurance underwriting and the phesician. Del Med 1986:58:411-9.

2 Waluen-Jones E(). Medical aspects of life insurance medicine and life assurance. Trans. Hed Soc Lond 1982-84:99-100:118-21.

3 Anonymous. Confidentiality and insurance companies. Fournal of the 11 dical Defince Lnon 1986;2:7.

+ Toon PD, Jones EJ. Scrring two masters: a dilemma in general practice. Lance 1986:i:1196-8

5 trno PS The conomic impact of AIDS. 7. A.11 1987;258:1376-7.

6 King MB. AIDS and the general practitioner: views of patients with HIV infections and AIDS. Br.11id f 1988:297:182-4.

Accepted 2.11 arch 1989

\section{Update box for Oxford Handbook of Clinical Specialties, p 209}

\section{The use of adrenaline in anaphylaxis}

Whenever immunisation or desensitisation procedures are in progress parenteral (intramuscular) adrenaline must be quickly available to treat anaphylaxis. The current edition of the British National Formulary' provides precise guidelines for the dose of adrenaline in children (see below). Some of the volumes of adrenaline $1 / 1000$ that it recommends - for example, $0.05 \mathrm{ml}$ for infants - are, however, too small to be given accurately by a $2 \mathrm{ml}$ syringe (the smallest that is likely to be immediately to hand), and during the emergency of anaphylaxis it is not convenient to dilute adrenaline (even if a compatible diluent is stocked). We therefore take the opportunity to adopt the doses of the formulary but recalculated for the readily available Min-I-Jet Adrenaline - a reasonably cheap preparation that has a 10th the concentration of adrenaline - that is, $1 / 10000$ $(100 \mu \mathrm{g} / \mathrm{ml})$ - and a short (not intracardiac) needle on a $10 \mathrm{ml}$ syringe.

\begin{tabular}{|c|c|}
\hline Age (months) & Dose $(\mathrm{ml})^{\star} \dagger$ \\
\hline $\begin{array}{l}3-5 \\
6-11 \\
12\end{array}$ & $\begin{array}{l}0.5 \\
0.75 \\
1.0\end{array}$ \\
\hline
\end{tabular}

In children over 1 year use the ordinary $1 / 1000$ preparation of adrenaline $(0.01 \mathrm{ml} / \mathrm{kg})$, as shown below.

Intramuscular dose of adrenaline (1/1000) in children and adults

\begin{tabular}{lc}
\hline Age (years) & Dose $(\mathrm{ml})$ \\
\hline 5 & $0 \cdot 25$ \\
12 & $0 \cdot 5$ \\
Adult & $0 \cdot 5-1 \cdot 0$
\end{tabular}

J M LONGMORE

1 British Medical Asseciation and Roval Pharmaceutical Society of Great Britain. British National Formulary 1988;No 16:129. 